\title{
Penerapan Manajemen Bandwith Menggunakan Hierarchical Token Bucket Di PT. Bukit Energi Servis Terpadu
}

\author{
Alvin Riady \& Aan Restu Mukthi \\ Fakultas Teknik Ilmu Komputer, Universitas Bina Darma \\ Email: Cimbitan07@gmail.com
}

\begin{abstract}
PT. Bukit Energi Servis Terpadu (BEST) is a company engaged in Operation \& Maintenance (O\&M) services which are members of the PT group. Bukit Asam Tbk. PT. Bukit Energi Servis Terpadu (BEST) already has a computer network in the form of adequate wired and wireless networks and has been connected to the internet. The bandwidth used for the scope of the office uses a bandwidth of $30 \mathrm{Mbps}$, but the problem of internet speed is not maximized where there is download activity and video streaming which causes the internet bandwidth in the office to be slow, thus affecting the activities of employees who are accessing the internet in the office either through wired networks and wireless internet hotspots. The results of the measurement of packet loss parameters (\%) after Bandwidth Management with HTB is better, namely $0.12 \%$ while before Bandwidth Management with HTB is carried out with a value of $0.52 \%$. The results of measuring the throughput parameters before using Bandwidth Management with HTB where the use of throughput after using Management Bandwidth with HTB obtained results of $624.9 \mathrm{kbps}$ while the throughput before Bandwidth Management was carried out was $624.4 \mathrm{kbps}$. By limiting bandwidth using the Hierarchical Token Bucket (HTB) facility, bandwidth can be divided into certain sections or prioritized for those who need higher internet speeds, while those that do not require an internet connection are provided with a small speed.
\end{abstract}

Keyword : bandwidth, download, Hierarchical Token Bucket (HTB), delay, packet loss, throughput

\section{Pendahuluan}

Penggunaan teknologi jaringan komputer yang lebih sederhana dapat dijumpai pada perusahaan-perusahaan, warung-warung internet, maupun di rumah-rumah yang biasanya merupakan pengguna layanan internet dari Internet Service Provider (ISP) tersedia. Layanan internet seperti ini dapat diperoleh melalui kabel maupun nirkabel (wireless) yang nantinya sama-sama akan diterima oleh sebuah modem. Dari modem inilah para pengguna (user) dapat menikmati layanan internet yang diberikan.

Managament bandwidth dapat dilakukan dengan menggunakan sebuah router. Router adalah perangkat yang akan melewatkan paket IP dari suatu jaringan ke jaringan yang lain, menggunakan metode addressing dan protocol tertentu untuk melewatkan paket data. Salah satu router yang dikenal saat ini adalah MikroTik Router. MikroTik Router dapat berupa perangkat keras yang didalamnya telah tersedia Router OS (operating system) yang digunakan pada routerboard. MikroTik Router juga bisa diinstal ke dalam sebuah PC (personal computer) sehingga dapat berfungsi sebagai router. Salah satu metode nya adalah Metode Hierarchical Token Bucket (HTB) merupakan salah satu metode Management Bandwidth dengan membuat teknik antrian lebih terstruktur dengan melakukan pengelompokan-pengelompokan bertingkat. Teknik antrian HTB memberikan fasilitas klasifikasi priority. Klasifikasi merupakan cara memberikan suatu kelas atau perbedaan pada setiap paket, hal ini dilakukan untuk mempermudah 
penanganan paket oleh antrian. Klasifikasi dilakukan dengan nilai dari parameter priority. Priority bertujuan untuk mengatasi permasalahan dominasi bandwidth antar pengguna dan bermacam-macam jenis trafik data ketika berjalan bersamaan.

PT. Bukit Energi Servis Terpadu (BEST) merupakan Perusahaan yang bergerak dibidang jasa Operation \& Maintenance $(O \& M)$ yang tergabung dalam grup PT. Bukit Asam Tbk. Berdirinya BEST ini dimulai dengan mendukung program energi nasional, saat ini BEST berfokus pada bidang jasa Operation \& Maintenance pembangkit listrik. PT. Bukit Energi Servis Terpadu (BEST) sudah memiliki jaringan komputer berupa jaringan kabel dan wireless yang memadai dan telah terkoneksi ke internet. Arsitektur jaringan di PT.Bukit Energi Servis Terpadu menggunakan topologi star dan topologi infrastruktur untuk jaringan wireless.

Adapun bandwidth yang digunakan untuk ruang lingkup kantor menggunakan bandwidth sebesar $30 \mathrm{Mbps}$ akan tetapi permasalahan kecepatan internet yang belum maksimal dimana adanya aktivitas download dan streaming video yang menyebabkan bandwidth internet di kantor tersebut menjadi lambat, sehingga mempengaruhi aktivitas karyawan yang sedang mengakses internet di kantor baik yang melalui jaringan kabel dan wireless internet hotspot. Adapun data awal yang diperoleh saat pengukuran adalah kecepatan download sebesar $0.49 \mathrm{Mbps}$ dengan delay sebesar $12 \mathrm{~ms}$. Salah satunya solusinya adalah mengatur kecepatan internet yang diperoleh dari ISP ( Internet Service Provider) atau lebih dikenal dengan nama managament Bandwidth.

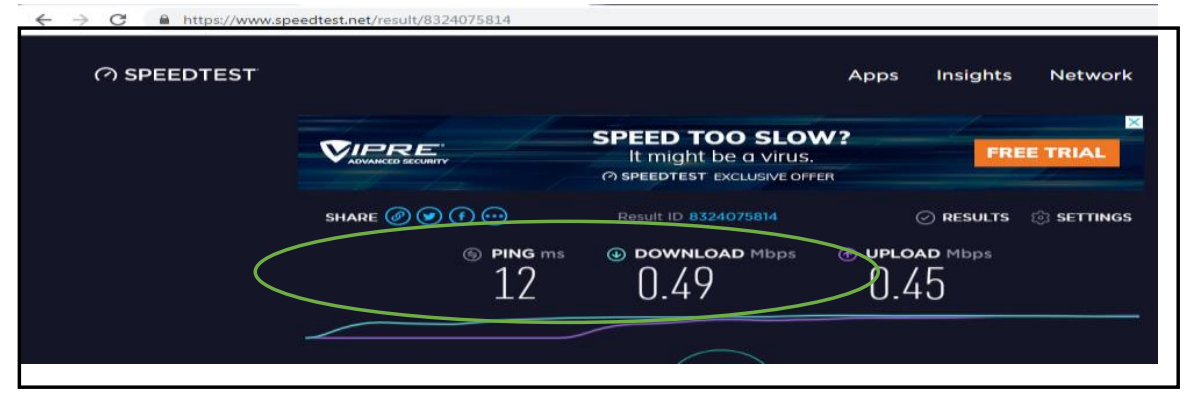

Gambar 1.1 Data Awal

Berdasarkan latar belakang di atas, penulis tertarik untuk meneliti "Penerapan Manajemen Bandwidth Menggunakan Hierarchical Token Bucket (HTB) di PT. Bukit Energi Servis Terpadu".

\section{Tinjauan Literatur}

\subsection{Bandwidth}

Menurut Towidjojo (2013) bahwa Bandwidth adalah kapasitas atau daya tampung kabel ethernet agar dapat dilewati trafik paket data dalam jumlah tertentu. Bandwidth juga bisa berarti jumlah konsumsi paket data per satuan waktu dinyatakan dengan satuan bit per second (bps). Bandwidth internet disediakan oleh provider internet dengan jumlah tertentu tergantung sewa pelanggan.. Dengan QoS dapat diatur agar user tidak menghabiskan bandwidth yang di sediakan oleh provider.

Menurut Athailah (2013) bahwa Manajemen Bandwidth adalah proses mengukur dan mengendalikan komunikasi (lalu lintas paket) pada link jaringan dengan memberikan alokasi saluran yang digunakan untuk proses upload maupun download sehingga 
penggunaan bandwidth masing-masing user di sebuah jaringan akan terdistribusi secara merata. Downstream adalah kapasitas mengambil data dari internet atau dikenal juga dengan nama download atau unduh, sedangkan upstream adalah kapasitas melakukan pengiriman data ke internet atau dikenal dengan nama upload atau unggah. Management Bandwidth dapat menerapkan layanan Quality Of Service (QoS) untuk menetapkan tipetipe lalulintas jaringan. sedangkan QoS adalah kemampuan untuk menggambarkan suatu tingkatan pencapaian didalam suatu sistem komunikasi data. Pengalokasian yang tepat dari suatu bandwidth untuk mendukung kebutuhan atau keperluan aplikasi atau suatu layanan jaringan. Pengalokasian bandwidth yang tepat dapat menjadi salah satu metode dalam memberikan jaminan kualitas suatu layanan jaringan QoS = Quality Of Services) (Antoni, Fikari \& Akbar, 2018; Antoni \& Akbar, 2019; Antoni, Jie \& Abareshi, 2020; Antoni, Herdiansyah, Akbar \& Sumitro, 2021).

\subsection{Hierarchical Token Bucket (HTB)}

Menurut Ketut (2020) bahwa Hierarchical Token Bucket (HTB) merupakan salah satu metode atau teknik antrian pada mikrotik yang dapat melakukan manajemen bandwidth dengan pola hirarki dan burst dari token bucket. Teknik antrian HTB memberikan fasilitas pembatasan traffic pada setiap level maupun klasifikasi. Bandwidth yang tidak terpakai bisa digunakan oleh klasifikasi yang lebih rendah. Fungsi HTB adalah menghasilkan struktur queue dengan bentuk hirarki dan mengatur hubungan antar kelas-kelas hirarki.

HTB mempunyai 3 jenis kelas antara lain root, inner, dan leaf.

a. Root class merupakan kelas yang berada diatas hirarki dan semua trafik keluar melalui kelas ini.

b. Inner class merupakan kelas yang memiliki kelas parent dan kelas child. Kelas ini mempunyai fungsi untuk menyampaikan informasi bagaimana bandwidth yang lebih untuk kelas child yang menyertainya.

c. Terakhir adalah kelas leaf adalah kelas sambungan yang berada dalam hirarki paling dasar.

\subsection{Quality Of Service ( QoS )}

Menurut Pratama (2014) bahwa Quality Of Service ( QoS ) merupakan sekumpulan teknik dan mekanisme yang menjamin performansi dari jaringan komputer (terutamanya di internet) di dalam penyediaan layanan keada aplikasi-aplikasi didalam jaringan komputer. Quality Of Service $(Q o S)$ dilihat dan diukur dari sudut pandang penyedia layanan. Berbeda dengan QoE ( Quality of Experience) dimana penilaiain dilakukan dari sudut pandang pengguna.

kumpulan dari beberapa parameter besaran teknis berdasarkan versi Tiphon yaitu :

a. Throughput

Merupakan lebar pita jaringan komputer yang menentukan kecepetan akses jaringan komputer atau kecepatan (rate) transfer data efektif, yang diukur dalam bps.

b. Packet Loss

Merupakan suatu parameter yang menggambarkan suatu kondisi yang menunjukkan jumlah total paket yang hilang, dapat terjadi karena collision dan congestion pada jaringan dan hal ini berpengaruh pada semua aplikasi karena 
retransmisi akan mengurangi efisiensi jaringan secara keseluruhan meskipun jumlah bandwidth cukup tersedia untuk aplikasi-aplikasi tersebut.

c. Delay(Latency)

Didefinisikan sebagai lamanya waktu yang diperlukan oleh paket data untuk samapai ke tujuan.

d. Jiter

Merupakan variasi dari delay, dimana terdapat perbedaan delay pada paket-paket yang dikirimkan padaaliran data ( data flow) yang sama

\section{Metode Penelitian}

\subsection{Waktu Penelitian}

Waktu penelitian dilakukan selama 4 Bulan dari Bulan Desember 2020 Sampai dengan Maret 2021.

\begin{tabular}{|c|c|c|c|c|c|c|c|c|c|c|c|c|c|c|c|c|}
\hline \multirow{3}{*}{ KEGIATAN } & \multicolumn{16}{|c|}{ Bulan / Tahun } \\
\hline & \multicolumn{4}{|c|}{$\begin{array}{c}\text { Desember } \\
2020\end{array}$} & \multicolumn{4}{|c|}{$\begin{array}{c}\text { Januari } \\
2021\end{array}$} & \multicolumn{4}{|c|}{$\begin{array}{c}\text { Februari } \\
2021\end{array}$} & \multicolumn{4}{|c|}{$\begin{array}{c}\text { Maret } \\
2021\end{array}$} \\
\hline & 1 & 2 & 3 & 4 & 1 & 2 & 3 & 4 & 1 & 2 & 3 & 4 & 1 & 2 & 3 & 4 \\
\hline Diagnosing & & & & & & & & & & & & & & & & \\
\hline Action Planning & & & & & & & & & & & & & & & & \\
\hline Action Taking & & & & & & & & & & & & & & & & \\
\hline $\begin{array}{l}\text { Evaluating } \\
\text { Learning }\end{array}$ & & & & & & & & & & & & & & & & \\
\hline $\begin{array}{l}\text { Pembuatan } \\
\text { Laporan }\end{array}$ & & & & & & & & & & & & & & & & \\
\hline
\end{tabular}

\subsection{Metode Pengumpulan Data}

Metode pengumpulan data yang digunakan dalam penelitian ini adalah (Fauzi, Dencik \& Asiati,2019):

a. Observasi (Data Pengukuran)

Pada metode ini peneliti mengumpulkan data dengan cara langsung melakukan pengukuran bandwidth meter serta data QoS yaitu parameter delay, packet loss dan throughput di Kantor PT. Bukit Energi Service Terpadu serta menggunakan nettools dan bandwidthmeter untuk memperoleh data yang sesuai dengan keadaan yang sesungguhnya.

b. Studi Kepustakaan

Pada metode ini penulis melakukan pengumpulan data dengan cara membaca dan mencatat buku atau literatur yang berhubungan dengan penelitian yang diambil.

\subsection{Metode Penelitian}


Menurut Kock (2017), Metode Action Research merupakan penelitian tindakan. Pendekatan ini dilakukan sendiri oleh peneliti yang bertujuan untuk mengembangkan metode kerja yang paling efisien. Metode Action research dibagi dalam beberapa tahapan, yaitu :

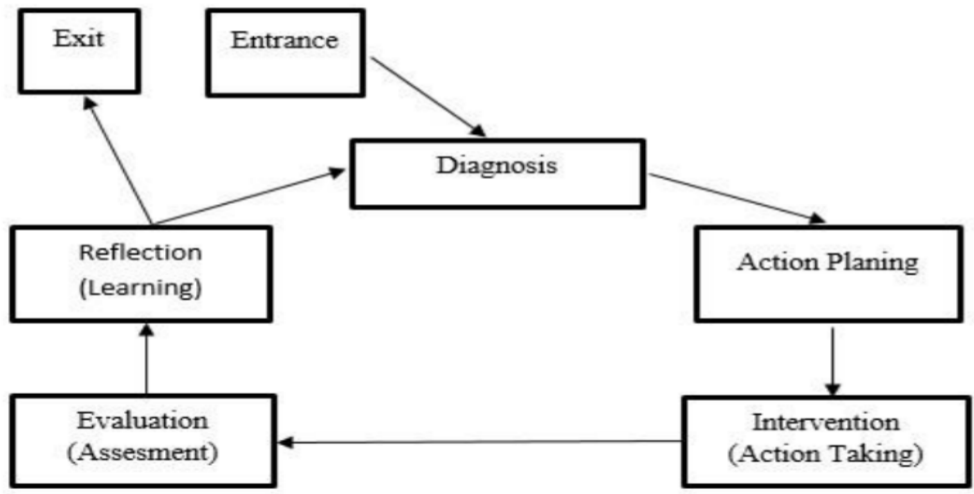

Gambar 3.1 Siklus Metode Action Reserch

\subsubsection{Diagnosis}

Upaya atau proses menemukan kelemahan atau penyakit (weakness, disease) apa yang dialami seseorang dengan melalui pengujian dan studi yang seksama mengenai gejalagejalanya (symptons).

\subsubsection{Perencanaan}

Peneliti memahami pokok masalah yang ada kemudian lanjutkan dengan menyusun rencana tindakan yang tepat untuk menyelesaikan masalah yang ada.

\section{Hasil dan Pembahasan}

\subsection{Hasil}

Hasil yang didapat sangat akurat, manajemen bandwidth menggunakan Metode Hierarchical Token Bucket (HTB) terbukti sesuai dengan yang didapat oleh client sesuai dengan konfigurasi rule di server $H T B$. Hasil pengukuran parameter delay sesudah dilakukan Management Bandwidth dengan HTB lebih baik yaitu 24.56 ms sedangkan sebelum dilakukan Management Bandwidth dengan HTB dengan nilai 51.24 ms. Hasil pengukuran parameter packet loss (\%) sesudah dilakukan Management Bandwidth dengan HTB lebih baik yaitu $0.12 \%$ sedangkan sebelum dilakukan Management Bandwidth dengan HTB dengan nilai $0.52 \%$. Hasil pengukuran parameter throughput sebelum dilakukan Management Bandwidth dengan HTB dimana penggunaan throughput sesudah dilakukan Management Bandwidth dengan HTB diperoleh hasil $624.9 \mathrm{kbps}$ sedangkan throughput pada sebelum dilakukan Management Bandwidth sebesar 624.4 kbps

\subsection{Pembahasan}

\subsubsection{Evaluation}

Dari Tabel 4.31 menunjukan hasil pengukuran parameter Delay (ms), Packet loss (\%), Throughput (KBps) dari setiap bagian atau ruang di PT. Bukit Energi Service Terpadu sebelum dilakukan Management Bandwidth dengan HTB untuk sampel pengukuran situs $w w w . b i n a d a r m a . a c . i d$ dengan nilai rata-rata $5 \mathrm{x}$ pengukuran, diperoleh hasil pengukuran 
rata-rata parameter delay sebesar $51.24 \mathrm{~ms}$, parameter Packet loss (\%) sebesar $0.52 \%$ sedangkan pada parameter Throughput (KBps) dengan nilai 624.4 kbps.

Tabel 4.2.1 Rata-rata Parameter $Q o S$ (Sebelum $M B$ )

\begin{tabular}{|c|l|c|c|c|}
\hline \multirow{2}{*}{ No } & \multirow{2}{*}{ Ruang / Bagian } & \multicolumn{3}{|c|}{ Rata-rata Parameter QoS } \\
\cline { 3 - 5 } & Delay (ms) & $\begin{array}{c}\text { Packet } \\
\text { Loss(\%) }\end{array}$ & $\begin{array}{c}\text { Throughput } \\
\text { (kbps) }\end{array}$ \\
\hline 1 & R.Direktur Utama & 56.6 & 1 & 624.4 \\
\hline 2 & R.Keuangan & 50.2 & 0.6 & 622.4 \\
\hline 3 & R.Pengembangan & 46.6 & 0 & 626.2 \\
\hline 4 & R.Teknik & 52.6 & 0.8 & 624.2 \\
\hline 5 & R.SDM \& Umum & 50.2 & 0.2 & 624.8 \\
\hline \multicolumn{2}{|c|}{$\begin{array}{r}\text { Rata-rata Seluruh } \\
\text { Bagian }\end{array}$} & 51.24 & 0.52 & 624.4 \\
\hline
\end{tabular}

Dari Tabel 4.32 menunjukan hasil pengukuran parameter Delay (ms), Packet loss (\%), Throughput (KBps) dari setiap bagian atau ruang di PT. Bukit Energi Servis Terpadu sesudah dilakukan Management Bandwidth dengan HTB untuk sampel pengukuran situs $w w w . b i n a d a r m a . a c . i d$ dengan nilai rata-rata $5 \mathrm{x}$ pengukuran, diperoleh hasil pengukuran rata-rata parameter delay sebesar $24.56 \mathrm{~ms}$, parameter Packet loss (\%) sebesar $0.12 \%$ sedangkan pada parameter Throughput (KBps) dengan nilai 624.9 kbps.

Tabel 4.2.2 Rata-rata Parameter $Q o S$ (Sesudah $M B$ )

\begin{tabular}{|c|l|c|c|c|}
\hline \multirow{2}{*}{ No } & \multirow{2}{*}{ Ruang / Bagian } & \multicolumn{3}{|c|}{ Rata-rata Parameter QoS } \\
\cline { 3 - 5 } & & Delay (ms) & Packet Loss(\%) & Throughput (kbps) \\
\hline 1 & R.Direktur Utama & 24.2 & 0 & 623.8 \\
\hline 2 & R.Keuangan & 24.2 & 0.2 & 625.2 \\
\hline 3 & R.Pengembangan & 24.2 & 0.2 & 624.4 \\
\hline 4 & R.Teknik & 25.2 & 0 & 624.8 \\
\hline 5 & R.SDM \& Umum & 25 & 0.2 & 626.4 \\
\hline \multicolumn{2}{|c|}{ Rata-rata Seluruh Bagian } & 24.56 & 0.12 & 624.9 \\
\hline
\end{tabular}

Dari hasil perbandingan pengukuran parameter Delay (ms), Packet loss (\%), Throughput (KBps) pada Tabel 4.33 menunjukkan bahwa parameter delay sebelum dan sesudah dilakukan Management Bandwidth dengan HTB untuk sampel pengukuran situs 
www.binadarma.ac.id dengan nilai rata-rata 5x pengukuran, diperoleh hasil pengukuran sesudah dilakukan Management Bandwidth dengan HTB lebih baik yaitu $24.56 \mathrm{~ms}$ sedangkan sebelum dilakukan Management Bandwidth dengan HTB dengan nilai 51.24 ms.

Tabel 4.2.3 Perbandingan Parameter $Q o S$

\begin{tabular}{|c|c|c|c|c|}
\hline \multirow{2}{*}{ No } & Kondisi & \multicolumn{3}{|c|}{ Parameter QoS } \\
\cline { 3 - 5 } & & Delay (ms) & Packet Loss(\%) & $\begin{array}{c}\text { Throughput } \\
(\mathrm{kbps})\end{array}$ \\
\hline 1 & Sebelum MB & 51.24 & 0.52 & 624.4 \\
\hline 2 & Sesudah MB & 24.56 & 0.12 & 624.9 \\
\hline
\end{tabular}

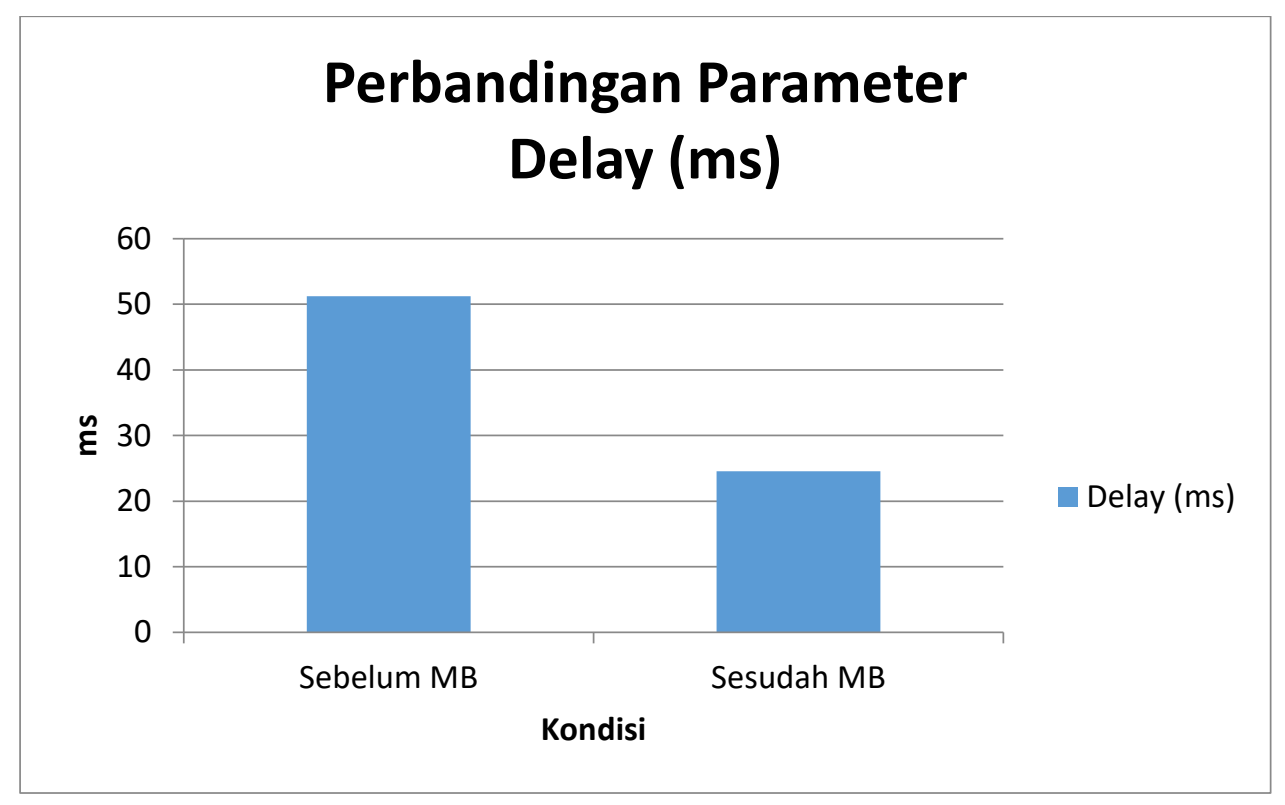

Gambar 4.2.5 Grafik Perbandingan Parameter Delay (ms) 


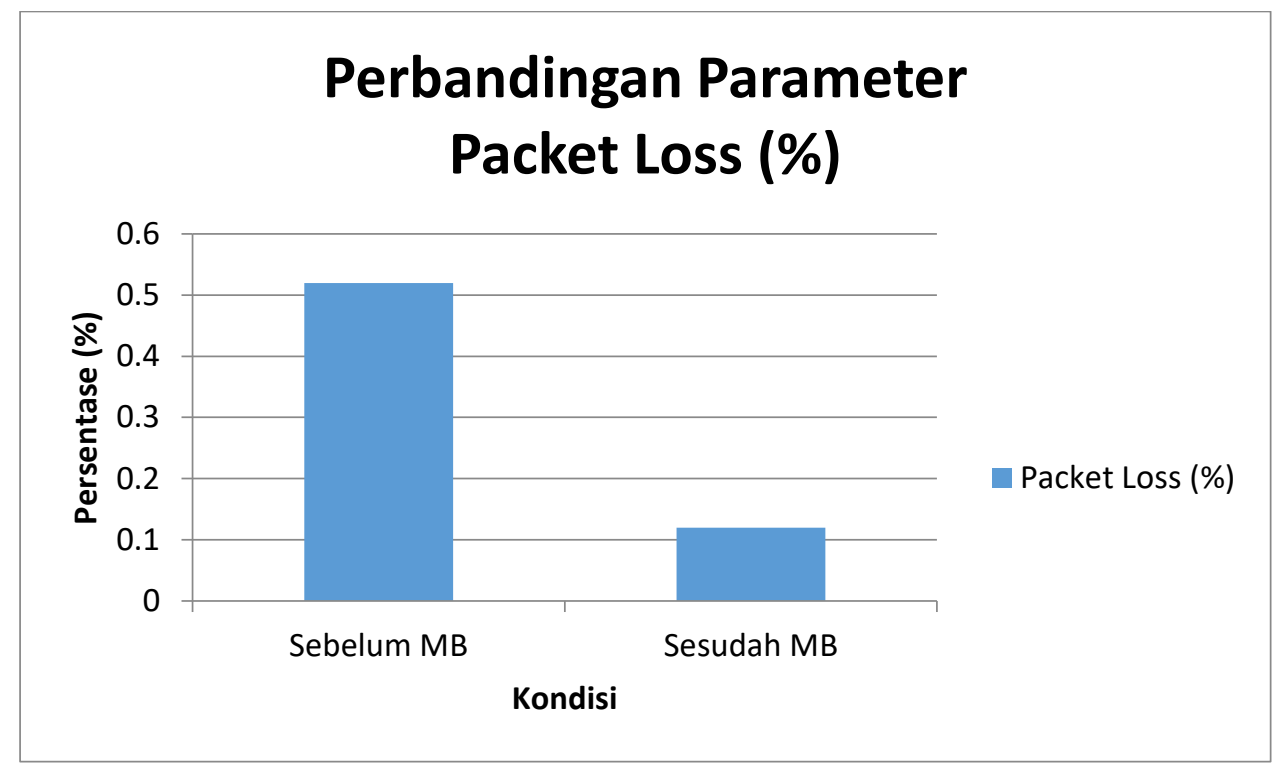

Gambar 4.2.6 Grafik Perbandingan Parameter Packet Loss (\%)

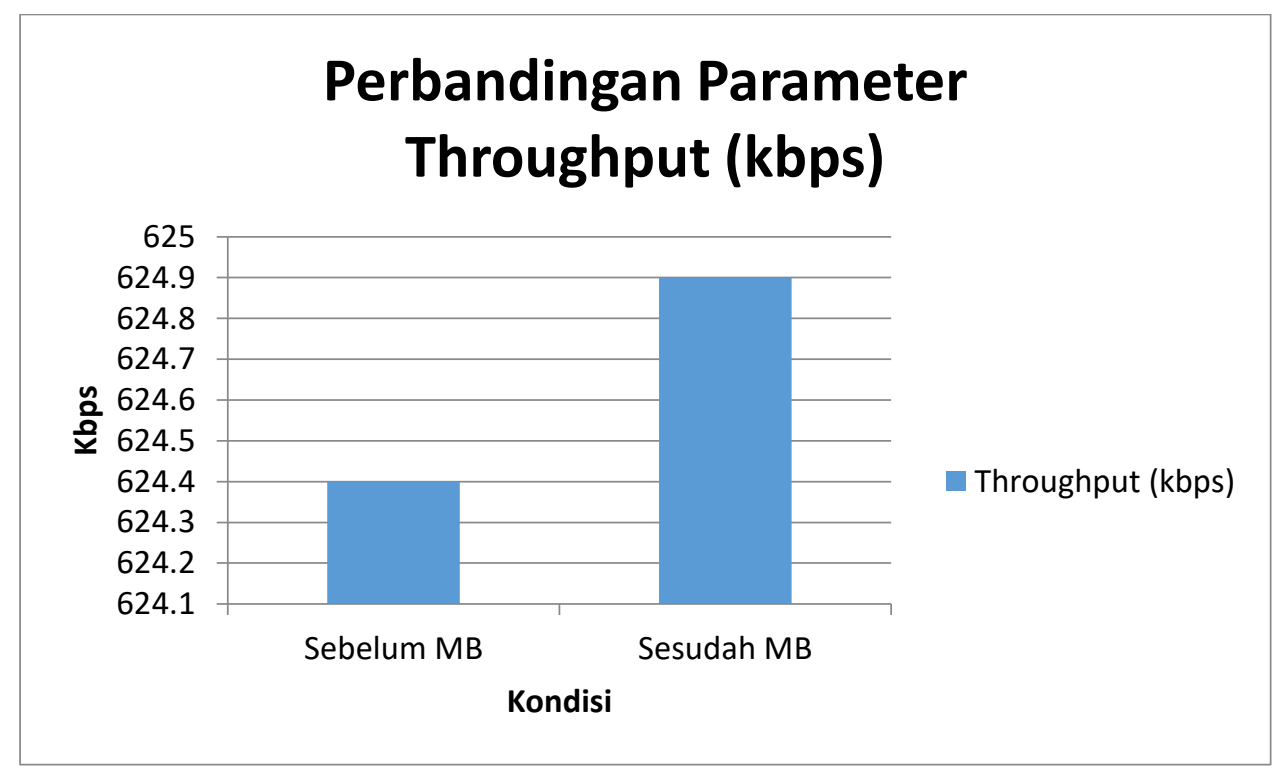

Gambar 4.2.7 Grafik Perbandingan Parameter Throughput (kbps)

Sedangkan pada pengukuran perbandingan parameter packet loss, sebelum dan sesudah dilakukan Management Bandwidth dengan HTB untuk sampel pengukuran situs www.binadarma.ac.id dengan nilai rata-rata $5 \mathrm{x}$ pengukuran pada setiap bagian, diperoleh hasil pengukuran sesudah dilakukan Management Bandwidth dengan HTB lebih baik yaitu $0.12 \%$ sedangkan sebelum dilakukan Management Bandwidth dengan HTB dengan nilai $0.52 \%$. Pada parameter pengujian Throughput menunjukkan dimana nilai bandwidth murni (aktual) sesudah dilakukan Management Bandwidth dengan HTB lebih baik dibanding sebelum dilakukan Management Bandwidth dengan HTB dimana penggunaan throughput sesudah dilakukan Management Bandwidth dengan HTB diperoleh hasil 624.9 kbps sedangkan throughput pada sebelum dilakukan Management Bandwidth sebesar $624.4 \mathrm{kbps}$. Dari hasil pembahasan analisis diatas terdapat beberapa faktor yang mempengaruhi hasil pengukuran terhadap parameter $Q o S$ yang terdiri dari 
Delay, Packet loss dan throughput dalam jaringan komputer yang bisa menyebabkan kestabilan akses antar titik jaringan terganggu serta lonjakan delay maksimum yang cukup tinggi pada saat tertentu .

\subsubsection{Learning}

Tahap ini merupakan bagian akhir siklus yang telah dilalui dengan melaksanakan review tahap-pertahap yang telah berakhir kemudian penelitian ini dapat berakhir. Seluruh kriteria dalam prinsip pembelajaran sudah dipelajari, perubahan dalam situasi saat pengukuran pengambilan data serta hasil yang didapat dievaluasi oleh peneliti dan dikomunikasikan kepada PT. Bukit Energi Servis Terpadu merefleksikan terhadap hasil penelitian, yang nampak akan dilaporkan secara lengkap dan hasilnya secara eksplisit dipertimbangkan dalam hal implikasinya terhadap penerapan metode Action Reaserch. Untuk hal tertentu, hasilnya dipertimbangkan dalam hal implikasinya untuk tindakan berikutnya dalam serta hasilnya juga dipertimbangkan untuk tindakan ke depan yang dapat dilakukan dalam kaitannya dengan domain penelitian, terutama akibat kegiatan yang terjadi diluar rencana awal dan cara di mana peneliti dapat melakukan penyelesaian kegiatan dan dalam hal implikasi untuk komunitas penelitian secara umum dengan mengidentifikasi keuntungan penelitian di masa datang.

\section{Kesimpulan}

Dari penelitian ini diperoleh kesimpulan adalah sebagai berikut:

Hasil yang didapat sangat akurat, manajemen bandwidth menggunakan Metode Hierarchical Token Bucket (HTB) terbukti sesuai dengan yang didapat oleh client sesuai dengan konfigurasi rule di server $H T B$. Hasil pengukuran parameter delay sesudah dilakukan Management Bandwidth dengan HTB lebih baik yaitu 24.56 ms sedangkan sebelum dilakukan Management Bandwidth dengan HTB dengan nilai 51.24 ms. Hasil pengukuran parameter packet loss (\%) sesudah dilakukan Management Bandwidth dengan HTB lebih baik yaitu $0.12 \%$ sedangkan sebelum dilakukan Management Bandwidth dengan HTB dengan nilai $0.52 \%$. Hasil pengukuran parameter throughput sebelum dilakukan Management Bandwidth dengan HTB dimana penggunaan throughput sesudah dilakukan Management Bandwidth dengan HTB diperoleh hasil $624.9 \mathrm{kbps}$ sedangkan throughput pada sebelum dilakukan Management Bandwidth sebesar 624.4 kbps.

Dengan membatasi bandwidth menggunakan fasilitas Hierarchical Token Bucket (HTB) maka bandwidth bisa dibagi ke bagian tertentu atau di prioritaskan bagi yang membutuhkan kecepatan internet yang lebih tinggi sedangkan bagian yang yang tidak memerlukan koneksi internet diberikan dengan kecepatan yang kecil.

Penggunaan sistem operasi linux server sebagai server gateway terbukti sangat handal terutama dalam hal kestabilan, kecepatan dan keamanan.

\section{Referensi}

Andi. (2010). Sistem Jaringan Komputer untuk Pemula. MADCOMS. Yogjakarta: Andi Offset

Antoni, D., \& Akbar, M. (2019). E-supply chain management value concept for the palm oil industry. Jurnal Sistem Informasi, 15(2), 15-29.

Antoni, D., Fikari, D., \& Akbar, M. (2018). The readiness of palm oil industry in 


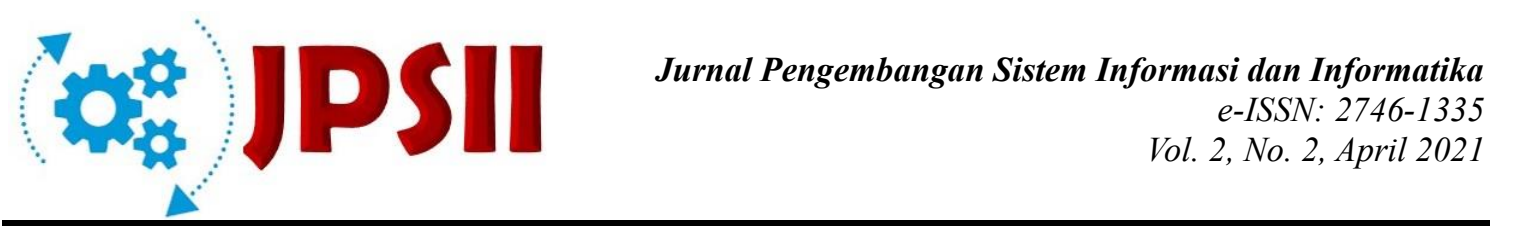

enterprise resource planning. Telkomnika, 16(6), 2692-2702.

Antoni, D., Herdiansyah, M. I., Akbar, M., \& Sumitro, A. (2021). Pengembangan Infrastruktur Jaringan Untuk Meningkatkan Pelayanan Publik di Kota Palembang. JURNAL MEDIA INFORMATIKA BUDIDARMA, 5(4), 1652-1659.

Antoni, D., Jie, F., \& Abareshi, A. (2020). Critical factors in information technology capability for enhancing firm's environmental performance: case of Indonesian ICT sector. International Journal of Agile Systems and Management, 13(2), 159-181.

Athailah. (2013). Panduan Singkat Menguasai Router Mikrotik untuk pemula.Jakarta

Fauzi, F., Dencik, A. B., \& Asiati, D. I. (2019). Metodologi Penelitian untuk manajemen dan akuntansi. Jakarta: Salemba Empat.

Herlambang Linto, Catur Azis. (2008). Panduan Lengkap Menguasai Router Masa Depan Menggunakan Mikrotik RouterOS. Yogyakarta:Andi Offset

Ketut, Gede. (2020). Penerapan Manajemen Bandwidth Menggunakan Metode Hierarchical Token Bucket Pada Layanan Hotspot Mikrotik Undiksha. CESS Juornal

Kock, Ned David Avison, and Julien Malaurent. (2017).” Positivist Information Systems Action Research: Methodolohical Issue. "Juornal of Managemen Infotmation Systems.

Mediakita

Pratama, Eka Agus I Putu. (2014). Handbook Jaringan Komputer ( Teori dan Praktek Berbasiskan Open Source. Bandung: Informatika.

Sugiyono. (2014). Teknik Pengumpulan Data. Metode Penelitian Kuantitatif, Kualitatif Dan R\&D. https://doi.org/10.3354/dao02420

Sunaga, H. (2002). TIPHON standardization activities in ETSI. NTT Review

Towidjojo, Rendra. (2013). Mikrotik Kungfu Kitab 2. Jakarta: Jasakom

Vol 5 No 1

\section{Copyrights}

Copyright for this article is retained by the author(s), with first publication rights granted to the journal.

This is an open-access article distributed under the terms and conditions of the Creative Commons Attribution license (http://creativecommons.org/licenses/by/4.0/) 